BULLETIN Bulletin hispanique

HISPANIQUE Université Michel de Montaigne Bordeaux

$115-2$ | 2013

Les traductions vieillissent-elles?

\title{
La distància temporal com a tercera llengua en traducció
}

Una aproximació teòrica

\section{Montse Corrius}

\section{(2) OpenEdition}

\section{Journals}

Electronic version

URL: http://journals.openedition.org/bulletinhispanique/2655

DOI: 10.4000/bulletinhispanique.2655

ISSN: 1775-3821

\section{Publisher}

Presses universitaires de Bordeaux

\section{Printed version}

Date of publication: 28 December 2013

Number of pages: $463-472$

ISBN: 978-2-86781-908-7

ISSN: 0007-4640

Electronic reference

Montse Corrius, "La distància temporal com a tercera llengua en traducció », Bulletin hispanique [Online], 115-2 | 2013, Online since 14 February 2017, connection on 06 May 2019. URL : http:// journals.openedition.org/bulletinhispanique/2655; DOI : 10.4000/bulletinhispanique.2655 


\title{
La distància temporal com a tercera llengua en traducció. Una aproximació teòrica
}

\author{
Montse Corrius \\ Universitat de Vic
}

Cet article a pour objet de présenter quelques approches théoriques de la traduction de la "troisième langue " (L3) - langue qui intervient dans le processus de traduction, différente de la L1 et de la L2, et qui ne représente ni la culture de départ ni celle d'arrivée - et de démontrer que la distance temporelle peut être considérée dans certains textes comme une troisième langue.

Mots-clés : traduction, troisième langue, distance temporelle.

El presente articulo tiene por objeto presentar unas aproximaciones teóricas sobre la traducción de la "tercera lengua» (L3) -lengua que interviene en el proceso de traducción, diferente a la L1 y a la L2, y que no representa ni la cultura de origen ni la de llegada-y demostrar que la distancia temporal puede ser considerada en algunos textos como tercera lengua.

Palabras claves: traducción, tercera lengua, distancia temporal.

This paper deals with some theoretical approaches on the translation of the "third language» (L3) -language that takes part in the process of translation, which is different from L1 and L2, and which does not represent either the source culture or the target culture - and aims at demonstrating that, on occasion, the temporary distance can be considered a type of third language.

Keywords: translation, third language, temporary distance.

\section{INTRODUCCIÓ: LA TERCERA LLENGUA}

Si bé és cert que actualment molts textos contenen més d'una llengua en la seva versió original, poques teories de la traducció han aprofundit en aquesta qüestió.

Bulletin Hispanique, Tome 115, nº 2 - décembre 2013 - p. 463-472. 
D'acord amb la teoria general de la traducció i tal com descriu Bassnett (1992:2) a la introducció del seu llibre Translation Studies, tota traducció suposa el trasllat d'un text escrit en una llengua de partida cap a una llengua d'arribada. Així doncs, quan parlem del procés de traducció, tendim a parlar de les dues llengües que intervenen en aquest procés: la llengua de partida (L1) i la llengua meta o d'arribada (L2); però ¿què passa quan el text original conté més d'una llengua? Aquest seria el cas de Jane Eyre de Charlotte Brontë, una novel.la anglesa que conté expressions en francès, o l'obra The Merry Wives of Windsor de William Shakespeare que també conté paraules i locucions en francès en la seva versió original, o Baudolino d'Umberto Eco que en la seva versió original italiana conté una llengua que el mateix autor es va inventar i que, com veurem més endavant, va crear problemes als traductors. Aquests exemples només en són una petita mostra però n'hi ha molts més ja que aquest fet s'ha donat al llarg de tota la història de la literatura. En totes aquestes obres la llengua de partida - o L1 - conviu, dins el text, amb una altra llengua diferent i que també cal tenir en compte en el procés de traducció. Aquesta llengua, que no és ni la L1 ni la L2, és la que anomenem «tercera llengua»o L3, i és la que fa que el procés binari de traducció [L1 $\rightarrow \mathrm{L} 2]$ es converteixi en un procés compost $\left[\mathrm{L} 1 \rightarrow \mathrm{L} 2 ; \mathrm{L}^{\mathrm{TO}} \rightarrow \mathrm{L}^{\mathrm{TM}}\right]$. Ara bé, no totes les diferents llengües que poden actuar com a tercera llengua dins un text són iguals, és a dir, no necessàriament són del mateix tipus ni tenen la mateixa naturalesa. Com hem pogut constatar anteriorment, la tercera llengua de Jane Eyre o The Merry Wives of Windsor és totalment diferent de la de Baudolino. Si bé aquesta darrera és una llengua inventada, la tercera llengua de les dues primeres (el francès) és una llengua existent. Podem classificar, doncs, la tercera llengua en a) llengua existent, quan aquesta correspon a una llengua d'una comunitat lingüística existent (pot ser una llengua estàndard, un dialecte o un registre); i b) llengua inventada, quan aquesta no correspon a cap llengua natural existent al món. La llengua inventada pot ser simplement una combinació de mots totalment inventats per l'autor, com ara la tercera llengua de Baudolino, o una combinació de paraules de diferents llengües naturals, per exemple el «Cityspeak» que apareix a la pel.lícula Blade Runner. El Cityspeak, que és una llengua que parla un dels personatges, Gaff, és una barreja de paraules i expressions de l'espanyol, el francès, el xinès, l'alemany, l'hongarès i el japonès. La frase que podem veure a continuació n'és una mostra:

Gaff: «Monsieur, azonnal Kövessen engem bitte.»

[Francès, hongarès, alemany]

(Senyor, seguiu-me immediatament, sisplau!)

\section{TRADUCCIÓ DE LA TERCERA LLENGUA}

La presència d'una tercera llengua en un text origen que és objecte de traducció, constitueix una restricció per als traductors. És evident que quan aquests estan duent a terme la seva tasca, es troben una sèrie d'obstacles o 
restriccions que segons Zabalbeascoa (1999:161) no permeten la traducció perfecta. El traductor no pot transferir tota la informació d'un text al mateix nivell, de manera que ha d'establir i jerarquitzar una sèrie de prioritats que poden variar depenent del tipus de restriccions existents en el text origen. El traductor ha de decidir quins aspectes del text ha de destacar o prioritzar en funció de tots els factors que intervenen en el procés de traducció com ara l'objectiu de la traducció, el tipus de públic a qui va adreçada, el context del text original, etc. En aquest sentit és necessari subratllar que la traducció d'una tercera llengua és simplement una de les moltes restriccions a les quals els traductors han de fer front quan porten a terme la seva tasca, però cal remarcar que la traducció d'una tercera llengua no té una única solució possible, sinó que cal decidir en quin grau la tercera llengua s'ha de manifestar a la traducció. Així, la solució pot anar des de distingir clarament la tercera llengua dins el text d'arribada fins a no marcar-la en absolut. En aquest darrer cas no hi hauria, doncs, diferència entre la L2 i la L3 a la traducció i, consegüentment, el lector no distingiria entre els dos grups representats en el text origen mitjançant la tercera llengua.

Considerant la tercera llengua com una restricció textual, podem establir una sèrie de criteris a fi de conèixer les solucions possibles per a la seva traducció. En primer lloc cal identificar la tercera llengua i decidir si és important transferirla al text d'arribada. Si no es considera apropiat, aleshores es traduirà com a L2. Tanmateix, si l'objectiu és destacar aquesta L3 dins el text d'arribada, hi ha diferents possibilitats. En aquest cas cal analitzar la naturalesa d'aquesta llengua i veure quina és la seva finalitat. En segon lloc, cal decidir com es pot transferir al text d'arribada i, per consegüent, establir els criteris per a la seva equivalència (similitud, igualtat). Finalment, cal crear el nou text. El conjunt de possibles traduccions d'una tercera llengua en un text multilingüe es pot resumir mitjançant el següent diagrama:

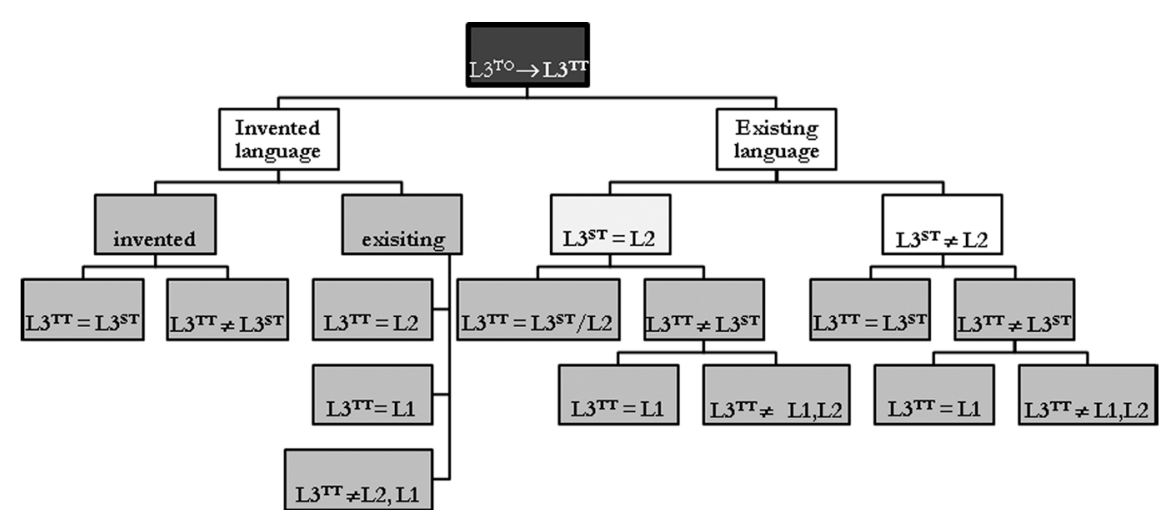


En aquest diagrama L1 representa la llengua principal del text origen, L2 la llengua principal del text meta, $\mathrm{L} 3^{\mathrm{TO}}$, la tercera llengua del text original i $\mathrm{L} 3^{\mathrm{TM}}$ la tercera llengua del text d'arribada. Pel que fa als colors, el blanc representa el text origen mentre que el gris representa el text meta.

$\mathrm{Si}$ ens fixem detingudament en aquest diagrama observarem totes les possibilitats de traducció d'una L3. Primerament cal saber si la L3 del text origen és una llengua real o inventada. En aquest últim cas hi ha dues possibilitats de transferència: d'una banda podem mantenir una llengua inventada en el text d'arribada o transformar-la en una llengua existent. En cas que la mantinguem inventada, aquesta pot ser igual o diferent de la utilitzada en el text meta. Si contràriament la transformem en una llengua existent, aquesta pot ser la mateixa que la L1, la mateixa que la L2, o una de diferent a qualsevol d'aquestes dues.

En cas que la L3 del text origen sigui una llengua existent, aquesta pot coincidir amb la llengua del text meta (L2) o no, i les possibilitats de traducció són les que podem observar a la banda dreta del diagrama. D'entrada, si la tercera llengua del text meta coincideix amb la L2, tenim dues possibilitats: la primera és mantenir exactament la mateixa llengua $i$, per tant, com que coincidiria amb la L2, el text d'arribada tindria únicament una llengua (L2); en altres paraules, la tercera llengua desapareixeria del text d'arribada. L'altra possibilitat seria emprar una L3 diferent de la utilitzada en el text origen (aquesta podria coincidir o no amb la L1). Per contra, si la tercera llengua del text origen no coincideix amb la llengua del text meta, la L2, es podria mantenir la mateixa L3 o utilitzar-ne una de diferent (que podria coincidir o no amb la L1).

Tal com hem pogut observar en aquest diagrama, la traducció d'una tercera llengua té múltiples possibles transferències i no cal dir que com més terceres llengües hi hagi en un text, més complicada serà la seva anàlisi i la seva traducció. És necessari aplicar el diagrama per a cada tercera llengua present en un text origen, ja que la inclusió de més d'una tercera llengua en un únic text no suposa que s'hagin de traduir totes de la mateixa manera. És més, fins i tot una mateixa llengua pot traduir-se de manera diferent al llarg del text, depenent de la finalitat d'aquesta en cada moment.

\section{AsPECTES CULTURALS, HISTÒRICS I TEMPORALS}

Fins ara hem parlat de la part més lingüística de la traducció, bàsicament hem fet referència a les llengües que intervenen en el procés de traducció, però encara no hem fet esment dels aspectes culturals, històrics i temporals, que tenen un paper primordial dins d'aquest procés i sense els quals la traducció no tindria sentit. A què ens referim quan diem això? Doncs bé, quan parlem de les dues llengües que habitualment prenen part en el procés de traducció (L1 i L2), -hem dit que la L3 només forma part de la traducció de textos multilingües- fem referència a unes llengües que representen una comunitat de parlants que pertanyen a una cultura en particular. Per tant, el traductor ha d'estar constantment al cas del contrast de la cultura representada per cada 
una de les dues llengües que intervenen en el procés de traducció. Tenint en compte, doncs, que la llengua és, en part, un reflex de la cultura, podem dir que la L1 és la llengua dels parlants de la cultura de partida mentre que la L2 correspon a la dels parlants de la cultura d'arribada. Dins del concepte de cultura, Nord (1997) i Santamaria (2001) distingeixen tres tipus de subcultures: la "paracultura» (les normes i convencions vàlides per a tota la societat), la «diacultura» (les normes i convencions vàlides per a un grup dins la societat) $\mathrm{i}$ la «idiocultura» (les normes i convencions vàlides per a un individu, dit d'altra manera, la cultura d'una persona individual). És evident que les cultures no són homogènies i que durant el procés de traducció s'hauria de transmetre aquesta heterogeneïtat. Les característiques culturals, anomenades "culturemes», han estat definides per Nord (1997) com un fenomen social d'una cultura X que és rellevant per als membres d'aquesta cultura, $\mathrm{i}$ quan aquest és comparat amb el fenomen social corresponent a la cultura $Y$, és evident que és específic de la cultura X. En el procés de comunicació intercultural, i per tant, en el procés de traducció, els culturemes poden causar problemes de comprensió i en conseqüència problemes de traducció. Com bé diu Vallverdú (1998) «des de sempre s'ha dit que la traducció té unes dificultats relacionades amb les diverses 'cosmovisions' de les llengües implicades». Per la seva part, Nida, el 1945, ja va examinar els diversos problemes de traducció i els va dividir en cinc grans blocs, els quals tenen a veure amb el concepte de cultura o les subcultures abans mencionades: 1) les dificultats relacionades amb l'ecologia (diferències de clima, geografia, vegetació, etc.), 2) les dificultats relacionades amb la cultura material (conreus, indústries, edificacions, etc.), 3) les dificultats relacionades amb la cultura social (entre d'altres l'organització social o les designacions de parentiu), 4) les dificultats relacionades amb la cultura ideològica com ara la religió o altres aspectes ideològics, i 5) les dificultats relacionades amb la cultura lingüística, és a dir les diferències que hi ha entre les llengües a nivell fonològic, morfològic, sintactic i lèxic.

Tanmateix, les característiques culturals no són l'únic problema amb què es troba el traductor. Tota obra literària està immersa en un moment històric i cultural concret. És a dir, està escrita en una llengua que representa una cultura d'un lloc en particular, i a la vegada està escrita en un moment concret de la història: en un temps. Steiner (1998) explica que en qualsevol acte de traducció, amb l'excepció de la traducció simultània, és fa un trasllat del passat al present, $\mathrm{i}$, per tant, aquest desplaçament hermenèutic no només creua la frontera lingüísticoespacial sinó també la del temps. Fontcuberta (1998) també fa referència al factor 'temps' quan parla de traducció. Concretament, ell esmenta els tres termes que intervenen en el procés de traducció: les dues llengües (L1 i L2) i la situació, que ve donada per totes les circumstàncies d'espai i temps que l'envolten, i en aquesta situació també hi inclou la persona de l'autor i del traductor, a més de les persones a qui va destinada la traducció. De fet, Venuti (2005) afirma que les opcions lèxiques i sintàctiques del traductor estan lligades a períodes específics de la història de la llengua utilitzada en la traducció, de manera que qualsevol traducció és una barreja de formes presents i passades 
que en constitueixen l'ús actual. Com més antiga sigui una traducció més es notarà, doncs, la dimensió històrica de la llengua.

No hi ha dubte que la distància temporal és un factor important en traducció, i sovint ha estat un obstacle per al traductor. Tal com apunta Hernández Guerrero (1993, 1999), a més dels nombrosos problemes existents en qualsevol procés de traducció, el fet de traduir una obra literària que pertany a una època llunyana incrementa notablement els problemes del traductor. El traductor no pot obviar la distància temporal entre el text original i la seva traducció de manera que ha de decidir, en termes generals, si intenta apropar el lector a al text original (amb totes les dificultats que això suposa) o si per contra apropa el text original al lector, destemporalitzant-lo i fent-lo més facilment llegible a un públic que està situat, en el temps, lluny de l'original (amb tots els seus inconvenients). Al llarg de la història s'han aportat una gran varietat de solucions. Pujol (2008), en el seu estudi sobre la traducció al català de l'oralitat fingida en el teatre de Shakespeare, ens mostra diverses solucions que han escollit alguns traductors catalans a l'hora de traduir el dramaturg anglès: des d' Anfòs Par, que utilitza un català medieval dels segles XIV i XV a l'hora de traduir el King Lear, fins a les traduccions de Josep Maria de Sagarra que s'apropen molt més al públic i a la llengua actual.

No obstant això, a vegades, la distància temporal la crea el propi autor. Així, l'autor fa servir una llengua específica per situar alguna part de l'obra o algun personatge en una època concreta. Aquest seria el cas d'algunes de les obres d'Umberto Eco com ara El nom de la rosa o Baudolino. En aquesta darrera obra, l'autor va crear una llengua pseudomedieval del nord d'Itàlia que va utilitzar en alguna part de l'obra i que, com el mateix Eco (2004) va assenyalar, va causar problemes de traducció, que es van resoldre de manera molt diversa en funció de la llengua d'arribada. La traductora espanyola, Helena Lozano, va intentar inventar-se una llengua que evoqués un text antic ple de préstecs i una cosa similar va fer la traductora catalana, Carme Arenas Noguera. D'altra banda, el traductor francès, Jean-Noël Shifano, va intentar trobar equivalents francesos satisfactoris tot i no aconseguir de transmetre l'atmosfera regional original. D’una manera similar, el traductor anglès, Bill Weaver, va utilitzar expressions angleses contemporànies. En canvi, el traductor alemany, Burchart Krober, va utilitzar diverses estratègies per als diferents problemes del text: algunes vegades germanitzava el text, utilitzant un mètode semblant al de Weaver, i altres vegades respectava les expressions originals. En definitiva, no hi ha cap traducció que respiri aquest tipus d'accent del nord d'Itàlia, i a la vegada esdevingui la llengua del jove i il.literat piamontès. A part de la creació d'aquesta llengua pseudomedieval, en els capítols on Eco utilitza l'italià estàndard, hi podem trobar expressions vernaculars (seguides de la seva traducció italiana). Eco pensava que només els lectors de la mateixa zona les apreciarien, però creia que els altres lectors, almenys, podrien respirar l'accent regional original. 


\section{DistànCIA TEMPORAL I TERCERA LLENGUA}

En el cas de Baudolino aquesta llengua pseudomedieval inventada per Eco funciona com a tercera llengua dins el text (la L1 és l'italià i la L2 és el català en el cas de la traducció catalana o el castellà en el cas de la traducció espanyola). Tal com hem dit anteriorment, tant la traductora catalana com l'espanyola van optar per inventar-se una llengua que evoqués un text antic. La traductora a l'espanyol, Helena Lozano (2006), va subratllar que igual que els escriptors a vegades creen un llenguatge nou, els traductors, per les seves finalitats expressives, també tenen necessitat de fer-ho i per això creen neologismes. Tenint en compte que el primer capítol conté un llenguatge totalment inventat per l'autor, un italià imaginari que pretén ser una llengua pseudomedieval, Lozano (2006) va optar per inventar-se un espanyol que recordés el Cantar de mio Cid i la Fazienda de Ultramar. En qualsevol cas va descartar introduir variants dialectals o variants diastràtiques, i, en canvi, va decidir utilitzar un castellà castís i arcaic. La caracterització dialectal present en la versió original va quedar completada (en la traducció) mitjançant l'assimilació fonètica de termes del dialecte piamontès, en aquells casos en què el context en permetia la comprensió o aquesta no era imprescindible. La traductora catalana busca també l'arcaisme, però ho intenta més en la grafia que no pas en la llengua, camp que gairebé queda reduït a l'ús de les formes antigues «hai» en comptes de «he», al de «ab» i a la repetició insistent de «anc». També utilitza el provençal «eu», però la resta és un efecte més gràfic ${ }^{1}$. Per comprovar-ho, vegem l'inici del primer capítol de la versió espanyola «Baudolino empieza a escribir», i de la catalana «Baudolino comença a escriure».

\section{Baudolino empieza a escribir}

Ratispone Anno Dommini Domini mense decembri mclv kronica Baudolini apelido de Aulario

Ego io Baudolino de Galiaudo de los Aulari con ena cabeza ke semblat uno lione alleluja sien dadas Gratias al sinior ke me perdone

a yo face habeo facto la robadura más grant de la mia vida, o sea e cogido de uno escrinio del obispo Oto muchos folii ke a lo mellor sont cosas dela kancet cancilleria imperial et elos raspado kasi todos menos ke donde no ýbase et agora teneo tanta Pergamina per eschrevir lo ke quiero, osea la mia chrónika aunque non la se escrevire en latino

Baudolino comença a escriure

Ratispone Anno Dommini mense decembri mclv kronica Baudolini cognomento de Aulario.

Eu Baudolino de Galiundo de.ls Aulari ab na testa qe sembla un lleo alleluja sien dades Gratie al sinho qe.m perdoni

a yo face habeo facto el robatori mays gran de la meva vita aizi ai pres d.un scriptori

1. Informació proporcionada, mitjançant correu electrònic, per Jesús Aturo i Perucho, Catedràtic de Paleografia, Codicologia i Diplomàtica de la Universitat Autònoma de Barcelona. 
de.l bisbe Oto molts folii qe potser son cosez de la cancelleria imperial e ai gratat quasi_tots menys qe on no sortia e ara hai tan Pergami per scriure.l qe vuy o sigui la mia chronica anc no se scriure.n llati

Així doncs, si reprenem el diagrama que hem vist anteriorment, veurem que tant l'opció de Lozano com la d'Arenas Noguera correspondria a la part esquerra del diagrama. Tenim una llengua inventada que passa al text d'arribada com a llengua inventada, però diferent de la del text origen $\left(\mathrm{L}^{\mathrm{TO}} \neq \mathrm{L} 3^{\mathrm{TM}}\right)$.

La llengua pseudomedieval de Baudolino és un clar exemple de L3. A banda d'haver estat inclosa amb la finalitat de crear un distanciament temporal dins del text, aquesta és una llengua inventada, com podria ser qualsevol altra L3 inventada sense aquesta finalitat. Podríem afirmar, doncs, que aquesta distància temporal és «fictícia», però ¿podríem dir que la distància temporal «real» pot ser considerada com una tercera llengua?

Si considerem, tal com hem dit anteriorment, que la tercera llengua és una llengua diferent de la L1, i diferent de la L2, podríem dir que la distància temporal es podria tractar com a L3 en el sentit que la llengua utilitzada pertany a una època, en la qual hi existia una cultura, que ja forma part del passat, i per tant ni la suposada cultura de partida ni la suposada cultura d'arribada actuals s'hi poden sentir plenament identificades. La L1 (del passat) té unes peculiaritats que la fan diferent de la corresponent L1 del moment actual. Per exemple, l'anglès utilitzat per Shakespeare (s. XVI, XVII) és diferent de l'anglès contemporani (del s. XXI). És únicament en aquest sentit que el tractament pot ser similar.

Davant un text amb una llengua de partida (L1) i amb un cert distanciament temporal $\left({ }^{\mathrm{DT}}\right)$ de la seva traducció, el traductor pot optar per fer arribar el text a la cultura d'arribada mitjançant una llengua (L2) contemporània $\left(\mathrm{L}^{\mathrm{DT}} \rightarrow>\mathrm{L} 2\right)$. Pot intentar trobar un equivalent en la llengua d'arribada, o sigui intentar reproduir sistemàticament una llengua tan antiga com la del text origen $\left(\mathrm{L}^{\mathrm{DT}} \rightarrow \mathrm{L} 2^{\mathrm{DT}}\right)$. N'és un exemple la traducció del King Lear d' Anfòs Par el 1912, en la qual el traductor va optar per utilitzar un català medieval de manera sostinguda (Pujol, 2008), o la traducció de Hamlet al francès, en la qual Marcel Schwob (traductor del s. XIX) va utilitzar el francès del segle XVI justificant en el seu pròleg que Shakespeare va pensar i escriure sota el mandat de Henri IV i Louis XIII (Hernández, 1999). També pot fer arribar el text mitjançant una L2 contemporània i acolorir-la de la seva època i civilització incloent-hi alguns elements, com arcaismes, que marquin certa distància temporal $\left(\mathrm{L}^{\mathrm{DT}} \rightarrow \mathrm{L} 2 / \mathrm{L} 2^{\mathrm{DT}}\right)$.

En definitiva, igual que en la L3, un text amb un distanciament temporal envers la seva traducció, no té una única solució possible de manera que el traductor ha de decidir, voluntàriament $\mathrm{o}$ involuntària, en quin grau aquest distanciament s'ha de manifestar en el text d'arribada. La solució pot anar des de distingir clarament la temporalitat fins a no marcar-la en absolut, el què Mounin (1994) va anomenar "vasos transparents», en altres paraules: traduir l'obra sense donar-li l'acoloriment de la llengua, ni de l'època, ni de la civilització original. 


\section{Conclusions}

Concloent, no podem obviar que tot text està immers en un moment històric i cultural concret, i està escrit en una llengua que representa una comunitat de parlants. Com més antic sigui el text, més distant sigui la cultura i més llunyana sigui la llengua, més gran serà la distància entre el text original i la seva traducció, i, per tant, més dificultats tindrà el traductor per portar a terme la seva tasca.

$\mathrm{Ni}$ els lectors del text origen ni els lectors del text d'arribada se senten identificats amb la llengua i la cultura que un text antic pot representar, i el mateix passa amb la tercera llengua. És per això que amb molta precaució $\mathrm{i}$ molts matisos podem tractar la distància temporal com a tercera llengua.

Aquesta distància temporal és una restricció que el traductor ha de considerar i, de la mateixa manera que fa amb la tercera llengua, ha d'establir i jerarquitzar les seves prioritats. Ha de decidir fins a quin punt li interessa destacar aquesta distància dins el text d'arribada i en funció d'aquesta decisió pot optar entre diverses solucions que van des de marcar clarament aquesta distància dins el text fins a no marcar-la en absolut.

Cada etapa de la producció i recepció d'una traducció està marcada pel seu moment històric, i això fa que diversos traductors d'una mateixa obra al llarg de la història hagin optat per solucions molt diferents. De fet, hi ha un gran nombre d'estudis que constaten aquesta qüestió. ¿’Podem dir, doncs, que les traduccions envelleixen, i que aquest envelliment fa que molts textos es tornin a traduir? Per a Hernández Guerrero (1999) la temporalitat fa que molts textos, sobretot literaris, s'hagin de tornar a traduir: les traduccions envelleixen i cada moment històric demana noves traduccions. Per contra, Desclot (2008) no creu que l'envelliment de la llengua d'una traducció sigui l'impuls primer que en propiciï una de nova. Una pregunta, doncs, de gran interès i que no té una única resposta.

\section{Referències bibliogràfiques}

Bassnett Susan, Translation Studies (Revised Edition), London, Routledge, 1992.

Desclot Miquel, "Retraduir els clàssics», Quaderns. Revista de traducció, 15, 2008, 8386.

Eco Umberto, Mouse or Rat?, London, Phoenix, 2004.

- Baudolino, Milano, RCS Libri D.p.A, 2000.

- Baudolino, Barcelona, Editorial Lumen, Trad. Helena Lozano Miralles, 2001.

- Baudolino, Barcelona, Edicions Destino, Trad. Carme Arenas Noguera, 2001.

- El nombre de la rosa, Barcelona, Editorial Lumen, 1980.

Fontcuberta Joan, «La traducció i el contacte entre llengües. Algunes consideracions», dins Bacardí Montserrat, Fontcuberta i Gel Joan, Parcerisas (eds.), Cent anys de traducció al català (1891-1990). Antologia, Vic, Eumo Editorial, 1998, 285-292. 
Hernández María José, «Marcel Schowb y el problema de la temporalidad en traducción", Quaderns. Revista de traducció, 3, 1999, 39-48.

- «El alejamiento cronológico entre el original y su traducción: Perspectiva histórica», Livivs, 3, 1993, 137-143.

Lozano Miralles Helena, "Cuando el traductor empieza a inventar: creación léxica en la versión española de Baudolino de Umberto Eco», Estudios de Neología. Actas del Congreso Internacional de Neología, 2006, 265-281.

Mounin Georges, Les Belles Infidèles, Paris, Presses Universitaires de Lille, 1994.

Nida Eugene, "Linguistics and ethnology in translation problems», Word, 1, 1945, 194-208.

Nord Christiane, Translating as a Purposeful Activity, Manchester, St. Jerome Publishing, 1997.

Pujol Dídac, «La traducción al catalán de la oralidad fingida en el teatro de Shakespeare», dins Jenny Brumme (ed.), La oralidad fingida: descripción y traducción. Teatro, cómic y medios audiovisuales, Madrid, Iberoamericana/Frankfurt, Vervuert, 2008, 115-134.

Santamaria Laura, Les referències culturals: aportació informativa $i$ valor expressiu. El subtitulat. Tesi doctoral presentada a la Facultat de Traductors i Intèrprets de la Universitat Autònoma de Barcelona, 2001.

Scott Ridley, Blade Runner. [DVD]. Ladd Company, 1982.

Steiner Georges, After Babel, Oxford, Oxford University Press, 1998 (3 ed.).

Vallverdú Francesc, "Els problemes de la traducció», dins Bacardí Montserrat, Fontcuberta i Gel Joan, Parcerisas Francesc (eds.), Cent anys de traducció al català (1891-1990). Antologia, Vic, Eumo Editorial, 1998, 305-317.

Venuti Lawrence, "Translation, History, Narrative», Meta: Translators' Journal, 50/3, 2005, 800-816.

Zabalbeascoa Patrick, "Priorities and Restrictions in Translation», dins Jeroen Vandaele (ed.), Translation and the (Re)Location of Meaning, Louvain, CETRA Publications, 1999, 159-167. 